\title{
NATION-WIDE BREAST CANCER SCREENING IN THE NETHERLANDS: SUPPORT FOR BREAST-CANCER MORTALITY REDUCTION
}

National Evaluation Team for Breast Cancer Screening (NETB), consisting of: Harry J. DE KONING ${ }^{1}$, Jacques FRACHEBOUD ${ }^{2}$, Rob Boer ${ }^{1}$, André L.M. Verbeek ${ }^{3}$, Hubertine J.A. Collette ${ }^{2}$, Jan H.C.L. Hendriks ${ }^{3}$, B. Martin VAN INEVELD ${ }^{1}$, Arry E. DE BRUYN ${ }^{1,4}$ and Paul J. VAN DER MAAS ${ }^{1}$ (Chairman)

${ }^{1}$ Dept. of Public Health, Erasmus Universiteit, Rotterdam; ${ }^{2}$ Dept. of Public Health and Epidemiology, Universiteit Utrecht; and ${ }^{3}$ Dept. of Epidemiology/Radiology, Katholieke Universiteit Nijmegen, Nijmegen, The Netherlands.

The nation-wide 2-yearly breast-cancer screening programme in The Netherlands, for women aged 50-69, started around 1988, and was predicted to result eventually in a $16 \%$ reduction in breast-cancer mortality in the total female population. We present the results of screening up to January 1,1993 , and compare these with the predicted results from the costeffectiveness analysis, on which basis this mortality reduction had been calculated. At least 550,000 women aged 50-69 were invited to screening in 1990-1992, and 75\% of these participated. Cancer was suspected from 5,162 examinations and further investigation was therefore required. Excision biopsy was done in $72 \%$ of referrals, and 2,515 breast cancers were detected. The results for 404,000 newly invited women compare favourably with expected values (in parentheses): $\mathbf{7 8 \%}$ attendance rate $(70 \%)$, $1.4 \%$ screen positive $(1.6 \%), 6.8$ cancers detected per 1,000 women screened $(6.4)$ and $38 \%$ of these cancers were DCIS or invasive carcinomas smaller than $11 \mathrm{~mm}$ in diameter $(36 \%)$. More data, e.g., on treatment and interval cancers, will follow in the years to come. These first results can be interpreted as strong early signs of a reduction in breastcancer mortality of at least the predicted size. Screening has sufficiently advanced the diagnosis, as well as or better than expected. Breast cancers diagnosed in this age group without screening are diagnosed at a worse stage than expected. Unfavourable side-effects, especially false-positive referrals, might be kept lower than those reported in other countries. o I995 Wiley-Liss, Inc.

Nation-wide breast cancer screening at 2-yearly intervals started in the Netherlands around 1988, for women aged 50-69. After extensive consultation of several advisory committees, a completely new organization was set up with specialized screening units, a training programme for radiologists, radiographers and pathologists, central and uniform quality-control procedures and continuous outcome evaluation. In 1991 all regions of the country had started screening and at the end of $199370 \%$ of the target population had been invited (at least oncc). All mammographic screening trials have confirmed the expectation that screening for women aged 50-69 can lead to a reduction in breast-cancer mortality (UK Trial, 1993; Nyström et al., 1993). On the basis of earlier trial results, it was expected that a national 3-yearly screening programme for women aged 50-64 in the United Kingdom would yield a $25 \%$ reduction in breast-cancer mortality in the population invited (Wald et al., 1991 ), and that a 2-yearly programme for women aged 50-69 in The Netherlands would yield a $22 \%$ reduction in this age group (de Koning et al., 1991). But can these expectations be confirmed?

A detailed cost-effectiveness (CE) analysis was performed earlier, indicating the expected development of effects and costs over time. These figures were to be used as a yardstick to evaluate the results of the national programme (de Koning $e t$ al., 1991; de Koning, 1993). The NHS programme in the United Kingdom has published the first results on screening performance (Chamberlain et al, 1993).

The present study presents the results of the first years of the Dutch breast-cancer screening programme up to January 1 , 1993, including size and nodal status of the screen-detected cases. The results are compared with the predictions from the $\mathrm{CE}$ analysis in order to decide whether the programme requires any changes, at either the local or the national level. An analysis has been carried out on the clinical stage distribution of all other breast cancers diagnosed. In addition, an attempt has been made to evaluate whether the results support expectations concerning a reduction in breast-cancer mortality.

\section{MATERIAL AND METHODS}

For the screening programme, The Netherlands has been divided into 9 regions, each with a joint management board, consisting of regional health authorities responsible for invitation of the women and of comprehensive cancer centres responsible for follow-up of data from cancer patients. In each region, a number of specialized (static, mobile or semi-mobile) screening units exists. Women receive a personal letter of invitation (fixed date) on the basis of the municipal population registries. Those women who do not respond receive a reminder. At the initial examination, 2-view mammography is performed, and at subsequent rounds 1 -view. Films are developed immediately to enable the radiographer to decide whether an additional (cranial-caudal) view is required because of technical faults or difficulty in interpretation. The mammograms are evaluated independently by 2 radiologists at the central unit who have to reach consensus about advising referral. In case of suspicion of cancer, the woman is referred to her general practitioner who is responsible for further referral to an outpatient clinic for assessment, with standardized guidelines for screen-referred women. There is no selfreferral system in the Dutch screening programme.

All regions use an information and registration system, and the regional joint management board is responsible for regional process evaluation and for reporting of regional results. The National Evaluation Team for Breast-cancer screening has defined a minimum dataset that is required for continuous outcome evaluation at national level. The data have been collected and analyzed annually by the Team since 1990 . This report contains the data on population, invitations, screening, assessment and breast cancers diagnosed (by stage) in the years 1990-1992. Results are also reported separately for 1990-1991 and 1992 for any time trends. The very small number of newly screened women in 1988-1989 (approximately 10,000 ) is not taken into account here (de Koning et al., 1991). The data are compared with the estimates from the CE analysis, which was based on results of the randomized screening trials in Sweden and the trials in The Netherlands, using a validated breast-cancer screening model. The model takes into account the natural history of the disease, current epidemiologic knowledge, characteristics of the screening programme and possible regional differences. Finally, it is used to predict long-term reduction in mortality from early results

${ }^{4}$ To whom correspondence and reprint requests should be sent at: NETB, Department of Public Health, Erasmus Universiteit, P.O. Box 1738, 3000 DR Rotterdam, The Netherlands. Fax: (0)10-4366831.

Received: August 12, 1994 and in revised form November 24, 1994. 
of the programme, given estimates on improved prognosis for screen-detected cases obtained from randomized screening trials (van Oortmarssen et al., 1990; de Koning et al., 1991; Boer et al., 1994).

\section{RESULTS}

In the year $1990,11 \%$ of the total target population (per year) was invited; in 1991 and $199225 \%$ and $49 \%$ respectively. In the first years of the national programme at least 550,630 women aged 50-69 were invited for breast cancer screening (Table I). Of these women, $72 \%$ took immediate action and attended screening, whereas $3 \%$ needed a reminder to participate (accepted recall). The total number of women screened was actually 470,000 ; approximately 54,000 were either 49 or 70 years old. Of the women aged $50-69$, actually screened before January 1, 1993, 5,162 were referred for abnormalities suggestive of cancer. In 1,224 of these women, additional non-invasive procedures excluded a malignancy, while a further $3,713(0.9 \%$ of screened women) underwent biopsy. In 2,515 women $(2,689$ aged $49-70)$, breast cancer was detected by screening. In $3.5 \%$ of the referred women, follow-up was not known or no additional procedures had been performed (about $1 \%$ were women who refused to be registered). In 86 cases the result of additional procedures (mostly non-invasive) was not yet known at time of analysis.

These results are influenced by the fact that some women have been invited for subsequent screens. The regions around Nijmegen and Utrecht had been part of the experimental projects since 1974-1975. In these areas, in 1991, 60\% of all eligible women had already been invited at least once before. Table II subdivides the results for all regions together into "first screen" and "subsequent screens" (having had screening mammography earlier in the programme or in the experimental projects). The results for newly screened women are good: only $1.4 \%$ of women being referred for assessment without negatively influencing the detection rate $(6.8$ per 1,000$)$, which is 3 times the clinical incidence rate $(2.2 \mathrm{per} 1,000)$. These early outcomes compare favourably with expectations. The expected average attendance rate of $70 \%$ is met, slightly less women than expected are referred and the number of screendetected cancers is $5 \%$ higher than expected on the basis of national average incidence data. The predictive value of a positive screening result reaches $50 \%$, and $67 \%$ of histologic examinations of biopsies show malignant lesions; both figures

TABLE I - PERFORMANCE OF NATION-WIDE 2-YEARLY MAMMOGRAPHIC BREAST-CANCER SCREENING IN THE OGRAPHIC BREAST-CANCER SCREENING
NETHERLANDS FOR WOMEN AGED $50-69^{1}$

\begin{tabular}{lrr} 
& $1990-1991$ & 1992 \\
\hline (A) Population and participation & & \\
Total female population (all ages) & $7,586,000$ & \\
Annual target population (50-69) & 725,000 & \\
Invited & 261,827 & $288,803^{2}$ \\
Accepted call & 186,457 & $212,132^{2}$ \\
Accepted recall & 6,955 & $10,476^{2}$ \\
(B) Screening results & & \\
Screen positive (suspicious of & 2,354 & 2,808 \\
$\quad$ cancer) & & \\
Clinical mammography, ultrasound & 646 & 578 \\
and/or cytology only & 1,574 & 2,139 \\
Excision biopsy & 134 & 48 \\
No follow-up & 1,068 & 1,447 \\
Breast cancers detected & 43 & 43 \\
Assessment performed; result not & & \\
$\quad$ yet known & & \\
\hline
\end{tabular}

'Age at January 1.-2Results of one region not available/not included (175 screen-positives in 1991). are much higher than predicted on the basis of earlier Dutch experience. The results were quite similar in 1990, 1991 and 1992 respectively, and the numbers are sufficiently large to justify the conclusions drawn.

In contrast, relatively more women were initially being referred from subsequent screens without breast cancer being detected. The referral and detection rates in subsequent screens are lower than for newly screened women, as expected, but the predictive value of a positive screening test was "only" $36 \%$ in 1990-1991. Although still a very favourable achievement compared to results in many other countries, we would have expected it to be better than or at least similar to the findings from first screens. The result could be explained by the fact that, for some of the women (mainly subsequent screens) 2 types of referral were used: referral for biopsy in the case of strong suspicion of cancer, as well as advice for less invasive additional investigations in the case of less suspicious lesions. Consequently, the Table shows that the relative proportion of referred women who eventually needed a biopsy was much lower in this group. This alternative approach has been changed.

Another difference from the earlier expectations relates to the attendance rate by age category: a constantly decreasing trend by age had been seen in the earlier Dutch screening trials, consistent in each trial and through the years. In the present nation-wide programme, approximately $79 \%$ of newly invited women aged 50-64 attended screening and only in the oldest 65-69 category (newly invited) did it fall to $73 \%$.

Screening significantly advances the diagnosis. Table III compares the histology and size distribution of all 2,143 screen-detected cancers in newly screened women (for the most part newly invited) to the distribution of 4,093 breast cancers diagnosed clinically in The Netherlands in 1989/1990 in this age group, as registered in the regions through regional cancer registries. The 4,093 cases comprise either clinically diagnosed cases in 1989/90 in regions that started screening in 1991, or all cases registered in 1990 excluding the screendetected cancers in regions that had already started screening. Patients from the regions around Nijmegen and Utrecht with experimental screening projects since the seventies are not included among the clinical cases.

In the screen-detected group $14 \%$ of the cancers are ductal carcinomas in situ, and the non-invasive and small invasive cancers (up to $10 \mathrm{~mm}$ ) amount to $38 \%$. In the clinical setting, the latter would have been $16 \%$ only (expected). Clearly, less than $20 \%$ of the screen-detected cancers are invasive and larger than $2 \mathrm{~cm}$ in diameter. Only the smallest invasive size category (up to $5 \mathrm{~mm}$ ) has been detected slightly less often than expected.

Another factor of importance in mortality change is that the national stage distribution of breast cancer in The Netherlands in 1989, which has become available (Netherlands Cancer Registry, 1992), is likely to be less favourable than expected earlier on the basis of (fewer) data from non-screened, clinically diagnosed cases in Utrecht and Nijmegen (Table III last column).

\section{DISCUSSION}

The results of nation-wide breast cancer screening in The Netherlands meet, or in some cases exceed the predictions made before the programme started. Since the programme is able to detect the expected total number of breast cancers at a significantly earlier stage at the first screen, the evidence available up to now shows the predicted reduction of $16 \%$ in the breast cancer mortality of the total female population to be realistic (de Koning et al., 1991). Invasive cancers smaller than $11 \mathrm{~mm}$ in diameter or DCIS have been detected slightly more 
TABLE II - OBSERVED RESULTS IN THE NATION-WIDE BREAST-CANCER SCREENING PROGRAMME FOR WOMEN AGED 50-69 IN THE NETHERLANDS COMPARED TO EXPECTED RESULTS; SUBDIVISION FOR FIRST SCREENS AND SUBSEQUENT SCREENS CARRIED OUT IN 1990-1992 1

\begin{tabular}{|c|c|c|c|c|c|c|}
\hline & \multicolumn{3}{|c|}{ First screen ${ }^{2}$} & \multicolumn{3}{|c|}{ Subsequent screen ${ }^{3}$} \\
\hline & $\begin{array}{c}\text { Observed } \\
1990-1991 \\
\end{array}$ & $\begin{array}{c}\text { Observed } \\
1992 \\
\end{array}$ & Expected & $\begin{array}{l}\text { Observed } \\
1990-1991 \\
\end{array}$ & $\begin{array}{c}\text { Observed } \\
1992 \\
\end{array}$ & Expected \\
\hline Screen positives (\% of screened women) & 1.4 & 1.4 & 1.6 & 0.9 & 0.7 & 0.6 \\
\hline Biopsy ( $\%$ of referred women) & 69.5 & 77.2 & 75 & 55.1 & 69 & 79 \\
\hline Breast cancer detection rate (per 1,000 women screened) & 6.6 & 6.9 & 6.4 & 3.1 & 3.5 & 3.8 \\
\hline Predictive value positive screening test (referral) $(\%)$ & 47.6 & 51 & 41 & 35.6 & 54.2 & 57 \\
\hline Biopsies with malignant diagnosis (\% of all biopsies) & 67.8 & 65.6 & 54 & 63.7 & 76.9 & 72 \\
\hline $\begin{array}{l}\text { Lymph-node metastases (\% of women with invasive screen-detected } \\
\text { cancer) }\end{array}$ & 28 & 33 & 28 & 28 & 26 & 24 \\
\hline
\end{tabular}

ISubsequent screen $=$ having had screening mammography before (in the programme or in the experimental projects).-.2 $\mathrm{N}=137,708$ in $1990-1991 ; 177,835$ in $1992 .-^{3} \mathrm{~N}=50,029$ in $1990-1991 ; 62,078$ in 1992 (there is a small difference in absolute number of women screened since these are all screens performed in 1990-1991 or 1992 only, compared to accepted (re-)calls in Table I, which may have actually been screened in the first months of 1992 or 1993).

TABLE III - HISTOLOGY AND TUMOUR SIZE DISTRIBUTION (\%) OF (IST) SCREEN-DETECTED VERSUS (LINICALLY DIAGNOSED BREAST CANCERS (WOMEN AGED 50-69) IN THE NETHERLANDS. OBSERVED RESULTS COMPARED TO EXPECTED DISTRIBUTIONS, ON WHICH BREAST CANCER MORTALITY

\begin{tabular}{|c|c|c|c|c|c|}
\hline & \multicolumn{3}{|c|}{ (1st) screen-detected } & \multicolumn{2}{|c|}{$\begin{array}{l}\text { Clinically } \\
\text { diagnosed }\end{array}$} \\
\hline & $\begin{array}{c}\text { Observed } \\
1990-1991 \\
\end{array}$ & $\begin{array}{c}\text { Observed } \\
1992 \\
\end{array}$ & Expected & Observed & Expected \\
\hline DCIS (ductal carcinoma in situ) & 13.0 & 13.9 & 11.3 & 4.0 & 4.2 \\
\hline Tla (invasive $\leq 5 \mathrm{~mm}$ ) & 3.6 & 4.3 & 8.1 & 1.4 & 4.1 \\
\hline $\mathrm{T} 1 \mathrm{~b}$ (invasive $6-10 \mathrm{~mm}$ ) & 22.0 & 19.1 & 16.6 & 6.1 & 7.7 \\
\hline Tlc (invasive $11-20 \mathrm{~mm}$ ) & 38.9 & 34.5 & 38.7 & 30.5 & 33.4 \\
\hline $\mathrm{T} 2^{+}$(invasive $>20 \mathrm{~mm}$ ) & 16.9 & 19.8 & 19.7 & 50.1 & 42.7 \\
\hline $\mathrm{Tx} /$ not (yet) classified & 5.6 & 8.4 & $5.6^{1}$ & 7.9 & $7.9^{1}$ \\
\hline
\end{tabular}

'If same \% taken into account as observed (in 1990-1991).

frequently than expected. These results also fulfil the tentative guidelines on detection rate, tumour size and nodal status, as put forward on the basis of the results in Kopparberg/ Ostergötland (Tabár et al., 1992). The small discrepancy regarding invasive cancers smaller than $5 \mathrm{~mm}$ in observed compared to expected percentages, in both screen-detected and clinically diagnosed cases, is likely to be due to classification problems during the '70-' 80 s in the Dutch trials.

In the ycars to come, more and other data are to be expected. Information about interval cancer rates from the nationally covered cancer registry(ies) as compared to the predicted rates will give a firm basis to decide whether the programme is able to detect a substantial proportion of all screen-detectable pre-clinical breast cancers. It already appears unlikely, from the detection rates and the size/histology distribution of screen-detected cases, that the interval cancer rate will be much different from that expected. It is not yet clear whether interval cancers will in general have a worse prognosis (Tabár et al., 1987; Ikeda et al., 1992), but with these first results presented, this is not expected to significantly influence the results on mortality reduction.

The first results are satisfying for several reasons. The invitation system is based on (100\% covered) municipal population registries and recall of non-participants. The low referral rates, combined with the high predictive value of a referral, show that the number of false positives can be minimized, thus refuting one of the principal objections raised by opponents of screening. Unfavourable consequences are apparently being limited, due to strict criteria for referral. In that respect, the results compare favourably with those of other countries where generally a 4-7\% referral rate is found (Chamberlain et al., 1993), although it should be noted that 2-view mammography is used in the Dutch programme. Our results, like the regional UK results, indicate that high detection rates are not dependent upon relatively high referral rates. The impact on workload and cost is proportionally lower. The higher UK referral rate, if reproduced in the Netherlands, would cause an extra 2 million Dutch guilders (\$1.2 million) annually for cost of assessment.

This analysis shows that the routine application of mammographic screening can attain quality levels that are comparable to those in experimental screening trials. We think that the use of specialized screening centres, the gradual build-up of the programme and the establishment of a National Expert and Training Centre for Breast Cancer Screening for the improvement of personnel and quality control have been decisive in attaining this result, together with the fact that extensive "reference" predictions were available beforehand.

These early results do not make a continuous monitoring and continuous adjustment of predictions superfluous. These first years have already shown the need for interpreting regional differences in order to keep one uniform, high-quality programme running throughout the country. In the build-up period, in particular, it is important to learn from regional policies, for instance regarding invitations to see which one produces relatively high attendance rates. In this phase adaptations can still be made and useful advice for new screening centres given. More importantly, it will take years before a significant impact on breast cancer mortality can be expected and any reduction may be partly obscured by "autonomous" mortality changes. The small decrease in breast cancer mortality visible in Sweden since 1980-1984 (La Vecchia et al., 1992) may be due to the large number of Swedish screening trials on hand since the seventies, but it is not conclusive without information on stage distributions of all breast cancers diagnosed, screen-detected or not, and on changes in adjuvant systemic treatment policy for all women with breast cancer diagnosed. It should be emphasized, also, that breast cancer screening is not an easy "export product" (Beemsterboer $\mathrm{et}$ al., 1994). Under optimal conditions, the balance between favour- 
able and unfavourable effects for the participating women will tip toward the former and the cost-effectiveness ratio will be relatively favourable compared to other health care provisions. But in countries with a lower breast-cancer incidence, with different health-care systems or without the possibility of maintaining very high quality standards, the cost-effectiveness ratio may be much higher and, especially when high quality standards cannot be guaranteed, breast-cancer screening there might still do more harm than good.

\section{ACKNOWLEDGEMENTS}

We acknowledge the assistance of the individual evaluators in the 9 regions, of the Working Group Evaluation and the
Coordinating Committee of the Health Insurance Executive Board, and of Mrs. P.M.M. Beemsterboer. Keeper of national data: Health Insurance Executive Board, Amstelveen. Regional data supplied by: Stichting Bevolkingsonderzoek Borstkanker Noord-Nederland, Groningen; Stichting Kankerpreventie IKA, Amsterdam; Stichting Vroege Opsporing Borstkanker, Enschede; Stichting Vroege Opsporing Borstkanker Midden-Nederland (Preventicon), Utrecht; Stichting Vroege Opsporing Kanker Oost-Nederland, Nijmegen; Stichting Kankerpreventie West-Nederland, Leiden; Stichting Bevolkingsonderzoek Borstkanker Zuid-West-Nederland, Rotterdam; Stichting Bevolkingsonderzoek Borstkanker Zuid, 'sHertogenbosch; Stichting Kankerpreventie en screening Limburg, Maastricht.

\section{REFERENCES}

BeEmsterboer, P.M.M., De Koning, H.J., Warmerdam, P.G., Boer, R., Swart, E., Dierks, M.-L. and Robra, B.-P., Prediction of the effects and costs of breast-cancer screening in Germany. Int. J. Cancer, 58, 623-628 (1994).

Boer, R., Warmerdam, P., de Koning, H. and van Oortmarssen, G., Extra incidence caused by mammographic screening [Letter]. Lancet, 343, 979 (1994).

Chamberlain, J., Moss, S.M., Kirkpatrick, A.E., Michell, M. and JoHnS, L., National Health Service breast screening programme results for 1991-2. Brit. med. J., 307, 353-356 (1993).

DE Koning, H.J., The effects and costs of breast cancer screening. (Dissertation). Erasmus University, Rotterdam (1993).

DE Koning, H.J., van Ineveld, B.M., van Oortmarssen, G.J., DE HAES, J.C.J.M., ColletTE, H.J.A., HeNDRIKS, J.H.C.L. and VAN DER MAAS, P.J., Breast cancer screening and cost-effectiveness; policy alternatives, quality of life considerations and the possible impact of uncertain factors. Int. J. Cancer, 49, 531-537 (1991).

IKedA, D.M., ANDERSSON, I., WatTsgärd, C., JANZON, L. and Linell, F., Interval carcinomas in the Malmo mammographic screening trial: radiographic appearance and prognostic considerations. Amer. J. Roentgenol., 159, 287-294 (1992).

La Vecchia, C., Lucchini, F., Negri, E., Boyle, P., Maison-Neuve, $P$. and LEVl, F., Trends of cancer mortality in Europe, 1955-1989. III. Breast and genital sites. Europ. J. Cancer, 28A, $927-998$ (1992).
NETHERLANDS CANCER REgisTRY. Incidence of cancer in the Netherlands 1989. SIG Health Care Information Utrecht (1992).

Nyström, L., Rutqvist, L.E., Wall, S., LindGREN, A., LindQVist, M., RydÉn, S., Andersson, I., BuUrStam, N., Fagerberg, G., FrISELl, J., TABÁR, L. and LARSSON, L.G., Breast cancer screening with mammography: overview of Swedish randomized trials. Lancet, 341, 973-978 (1993).

TABÁr, L. Fagerberg, G., Day, N.E. and Holmberg, L., What is the optimum interval between mammographic screening examinations? An analysis based on the latest results of the Swedish two-county breast cancer screening trial. Brit. J. Cancer, 55, 547-551 (1987).

Tabár, L., Fagerberg, G., Duffy, S.W., Day, N.E., GaD, A. and GRÖNTOFT, O., Update of the Swedish two-county program of mammographic screening for breast cancer. Radiol. Clin. N. Amer., 30, 187-210 (1992).

UK Trial of Early Detection of Breast Cancer Group. Breast cancer mortality after 10 years in the UK trial of early detection of breast cancer. Breast, 2, 13-20 (1993).

van OORTMarssen, G.J., Habbema, J.D.F., VAN der MaAs DE Koning, P.J., DE Koning, H.J., ColletTE, H.J.A., VerbeeK, A.L.M., GEERTS, A.T. and LuBBE, J.Th.N., A model for breast cancer screening. Cancer, 66, 1601-1612 (1990).

Wald, N., Frost, C. and CuCKLE, H., Breast cancer screening: the current position. Brit. med. J., 302, 845-846 (1991). 